KANSAS JOURNAL of MEDICINE

\section{Physician Burnout in a Rural Kansas Community}

Domonique Marquez-Cunningham¹, Emily Lenherr ${ }^{1}$, Emma Flynn', Joshua Warner' ${ }^{1}$, Rosey Zackula, M.A. ${ }^{2}$,

William Cathcart-Rake, M.D. ${ }^{1}$

${ }^{1}$ University of Kansas School of Medicine-Salina, Salina, KS ${ }^{2}$ University of Kansas School of Medicine-Wichita, Office of Research, Wichita, KS

Received March 20, 2019; Accepted for publication May 31, 2019; Published online Nov. 25, 2019

\section{ABSTRACT}

Introduction. Physician wellness and burnout are topics of intense discussion and study, however, less is known about rural physician burnout. The aim of this study was to assess levels of physician burnout in the rural Kansas community of Salina.

Methods. An electronic, confidential survey was conducted among 145 physicians with active privileges at the local health center and/or surgical center. The survey included demographic features, practice characteristics, and the abbreviated Maslach Burnout Inventory ${ }^{\mathrm{TM}}$ (aMBI). In addition, survey participants were invited to provide freetext responses to questions concerning specific causes of burnout and mechanisms to combat feelings of burnout.

Results. Of 145 invited, 76 physicians completed the survey. Thirty-six respondents self-identified as primary care physicians, 22 as subspecialists, and 18 as surgeons. aMBI scores for emotional exhaustion (EE), depersonalization (D) and personal accomplishment (PA) ranged from 0 to 18 . The mean EE score was $8.4(\mathrm{SD}=$ 4.9), mean D score was $4.8(\mathrm{SD}=3.9)$, and mean PA score was 15.2 $(\mathrm{SD}=2.8)$. Using tertiles, physician burnout (i.e., those in the first tertile) for EE was 39\% (30/76), D was 34\% (26/76), and PA was $41 \%$ (31/75); $22 \%$ of physicians surveyed scored high on both EE and $\mathrm{D}$ as measured by tertiles, suggestive of more serious burnout. No significant differences in aMBI scores were observed for demographic features or practice characteristics; physicians who worked with medical students had higher PA scores. Contributing to burnout were demands of documentation and difficult patient encounters, while true time away might ameliorate rural physician burnout.

Conclusions. As measured by aMBI constructs, burnout is prevalent among the responding rural physicians practicing in the Salina community. Kans J Med 2019;12(4):109-116.

\section{INTRODUCTION}

Burnout is a term used to describe work-related stress characterized by emotional exhaustion, feelings of cynicism and detachment toward patients (depersonalization), and a low sense of personal accomplishment. ${ }^{1}$ The effects of burnout on the individual can be described by feelings of meaninglessness and ineffectiveness, and a tendency to view patients, students, and colleagues as objects rather than human beings. ${ }^{2}$ Burnout has serious consequences for the healthcare system, including decreased physician empathy, lower patient satisfaction and care quality, higher medical error rates and malpractice risk, higher physician and staff turnover, physician drug abuse and addiction, and physician suicide. ${ }^{3-7}$ Patients can be left feeling disillusioned about their caregivers, often feeling helpless and defeated by the care they receive. ${ }^{8}$ It is imperative that physician burnout be studied and addressed.

Measuring burnout is challenging. Several surveys have been validated to measure burnout: Maslach Burnout Inventory-Human Services Survey for Medical Personnel (MBI-HSS), Oldenbury Inventory, Physician Work-Life Study's Single-Item, and Copenhagen Burnout Inventory. ${ }^{9}$ Each survey was developed for specific populations. MBI-HSS targets workers in human service/helping professions and includes national benchmark data for U.S. physicians. ${ }^{10}$ A shorter version of the survey, the abbreviated Maslach Burnout Inventory (aMBI), is an effective alternative to the full MBI. ${ }^{11-14}$ The MBI and the aMBI have been used to study burnout for various physician cohorts, but less is known about physician burnout in rural areas. While no standard exists for a dichotomous burnout classification for either the MBI or aMBI, options have been proposed, including tertiles and standardized $z$ values. ${ }^{75-17}$ Both measures are dependent on the target population and are recommended in critical boundary calculations. Mind Garden, publisher of the MBI, cautions against using cut-off scores for burnout, claiming they have no diagnostic validity. ${ }^{18}$ Nevertheless, the use of cut-offs has not been discarded completely, may be of value in identifying individuals prone to burnout, and are essential when comparing the results of various studies.

In addition to exploring the prevalence of burnout in the Salina community, any association between teaching medical students and/ or residents and physician burnout was a topic of interest. In a previous study, Adams and Cathcart-Rake ${ }^{19}$ surveyed attending physician perceptions of teaching medical students at the University of Kansas School of Medicine regional medical campus (RMC) in Salina. Of the 62 physicians who completed the survey, 92\% enjoyed having medical students in the clinic/hospital, $81 \%$ agreed that having a medical student working with them was personally beneficial, and $72 \%$ agreed that the presence of medical students increased their job satisfaction, while $22 \%$ remained neutral on this issue, and $6 \%$ disagreed or strongly disagreed that medical students increased their job satisfaction. Is it possible that participation as a medical educator for the Salina RMC or the residency program contributes to physician wellness or decreases physician burnout?

This study was designed to explore physician burnout in a rural community and the association between physician burnout and teaching medical students. The primary objective was to measure the three domains of burnout (utilizing the aMBI) and evaluate associations with demographic and practice characteristics in a rural setting. A second objective was to measure the extent to which teaching medical students and residents may influence burnout levels of rural physicians. 


\section{METHODS}

Setting. Salina is a rural community located in north central Kansas with a population of approximately 48,000. The medical community is comprised of approximately 150 physicians representing most disciplines (e.g., family medicine, internal medicine and medicine subspecialties, and surgery and surgical subspecialties, pathology, radiology, anesthesiology). In addition to outpatient services, most Salina physicians care for patients at the Salina Regional Health Center (SRHC), a 212 bed, not-for-profit hospital system, and/or the 16 bed Salina Surgical Hospital (SSH), a joint venture of SRHC and a group of local physicians. Many physicians also provide face-to-face care for patients in outreach clinics within the surrounding 14 counties. Salina is also home of the RMC of the University of Kansas School of Medicine. This full, four-year allopathic RMC opened in 2011 and admits eight medical students each year. ${ }^{20}$ Approximately 100 Salina physicians (two-thirds of the physicians with active privileges) have volunteer or part-time appointments at the RMC, and approximately 60 of the physicians with faculty appointments actively participate in medical school teaching activities. Many Salina physicians also participate in the supervision of family medicine residents training at Smoky Hill Family Medicine Residency Program.

Target Population and Inclusion Criterion. The study population included all 145 physicians who had active hospital privileges (SRHC and/or SSH) within the local community. The total number included physicians directly employed by SRHC, physicians at Salina Family Healthcare Center (a Federally Qualified Health Center), and physicians in private practice within the rural community.

REDCap Online Survey. A REDCap (Research Electronic Data Capture) survey consisting of demographic and workplace characteristics, along with the aMBI questionnaire was administered to participating physicians. REDCap is a secure, web-based application designed to support data capture for research studies, providing: (1) an intuitive interface for validated data entry; (2) audit trails for tracking data manipulation and export procedures; (3) automated export procedures for seamless data downloads to common statistical packages; and (4) procedures for importing data from external sources. ${ }^{22}$

Outcome Measures. Demographic and workplace characteristics collected in the survey included age, gender, years in practice, teaching status with the local RMC and/or the local family medicine residency program (Smoky Hill Family Medicine Residency), call schedule, and practice model (private practice versus hospital-employed physician). Physicians also were asked to identify themselves as a practitioner in one of three broad categories: primary care (family medicine, general internal medicine, pediatrics, emergency medicine, hospitalist), surgery (general surgery, orthopedics, urology, neurosurgery, cardiothoracic surgery, obstetrics/gynecology, anesthesiology), or subspecialty (cardiology, hematology/oncology, gastroenterology, infectious disease, pulmonology, critical care, psychiatry, pathology, radiology, nephrology, allergy/immunology, neurology, physical medicine). Further categorization as to surgical or medical subspecialty was not done because in several instances only one or two Salina physicians in a specific subspecialty were
KANSAS JOURNAL of MEDICINE PHYSICIAN BURNOUT

continued.

identified and anonymity might be compromised. Respondents also had the opportunity to answer two open-ended questions: (1) "What causes you to feel burned out?" and (2) "What helps you feel less burned out?"

Burnout Survey Instrument. The aMBI is a 9-item instrument where respondents rate each item using a Likert type scale of 0 to 6 indicating the frequency with which each question applies: Every day, A few times a week, Once a week, A few times a month, Once a month, A few times a year, or Never. Scoring for the aMBI consists of tallying responses into three constructs, Emotional Exhaustion (EE), Depersonalization (D), and Personal Accomplishment (PA), each score ranging from 0 to 18 . Permission was obtained from Mind Garden, Inc. to administer the aMBI survey. (Complete details for scoring the aMBI can be found at https://www.integration.samhsa. gov/about-us/MaslachScoringAbbreviated.pdf).

Administration of Online Survey. One week prior to opening the survey, the 145 physicians with active privileges at SRHC and/ or SCC were sent an email providing details of the study and soliciting their participation in the survey. Potential respondents were reassured of anonymity of survey responses and informed that there were neither rewards for participation nor punishment for non-participation. Contact information for survey administrators and the Institutional Review Board (IRB) was included in this and all subsequent emails. One week following the initial recruitment email, the REDCap survey was opened. One week and two weeks after the survey was opened, follow-up emails were sent, encouraging participation in the survey. The survey was closed four days after the final reminder.

Statistical Analysis Plan. Three major elements or constructs of burnout were assessed: emotional exhaustion (EE), depersonalization (D), and personal accomplishment (PA). Continuous data and dichotomous cut-offs or cut-points for the constructs were analyzed across variables included in the survey. Three methods for constructing the cut-points for burnout were explored. The first utilized tertiles from the sample population, as described in previous studies of burnout. ${ }^{7,15,16}$ The second utilized the standardized $\mathrm{z}$ scores defined by Leiter and Maslach ${ }^{17}$ : High Exhaustion (EE) at $\mathrm{z}=$ Mean $+\left(\mathrm{SD}^{*} 0.5\right)$; High Cynicism (D) at $\mathrm{z}=$ Mean $+(\mathrm{SD} * 1.25)$; and High Professional Efficacy $(\mathrm{PA})$ at $\mathrm{z}=$ Mean $+(\mathrm{SD} * 0.10)$. The empirically determined cut-points for EE and D set by Lebares et al. ${ }^{22}$ was the third method employed; cut-points for high burnout and stress among U.S. surgery residents were: EE score $\geq 9$ and D score $\geq 6$. Finally, a PA score $\leq 12$ was chosen as a cut-point for high burnout; this cut-point indicated that on average physicians felt positive about their interactions with patients and colleagues no better than once per week on each of the three questions pertaining to this construct.

Descriptive statistics were used to summarize survey responses. To measure bivariate associations with the constructs, nonparametric tests were conducted in IBM SPSS statistics version 23; these 


\section{KANSAS JOURNAL of MEDICINE}

PHYSICIAN BURNOUT

continued.

included Chi-square, Mann-Whitney U, Kruskal Wallis, and Spearmen's rho. Nonparametric tests were selected because data were either skewed or categorical (where data were sparse, exact statistical tests were used). Two-tailed statistical tests with Bonferroni correction were used as the critical value. Answers to the two openended questions were compiled in Microsoft ${ }^{\oplus}$ Excel and sorted by similar answers or key words to reach a better understanding of the root cause of burnout in the surveyed population.

The University of Kansas Medical Center IRB reviewed and approved the study protocol.

\section{RESULTS}

One hundred forty-five physicians, 105 men (72\%) and 40 women (28\%), received an invitation to complete the survey. Fifty-nine of the 145 (41\%) were identified as primary care physicians, 48 (33\%) as subspecialists, and 38 (26\%) as surgeons. Seventy-six physicians completed the survey ( $52 \%$ response rate). Of the 76 respondents, 51 were men (67\%) and 25 were women (33\%). Thirty-six (47\%) of the respondents self-identified as primary care physicians, 22 (29\%) self-identified as subspecialists, and 18 (24\%) self-identified as surgeons. Demographic questions and Salina physician responses are summarized in Table 1.

Salina physician aMBI scores are summarized in Table 2. Mean EE score was $8.4(\mathrm{SD}=4.9)$ with a range of 0 to 18 . Mean D score was 4.5 $(\mathrm{SD}=3.9)$ with a range of 0 to 16. Mean PA score was $15.3(\mathrm{SD}=2.8)$ with a range of 4 to 18. Cut-points for high burnout using the three methods also are noted in Table 2. Most methods indicated similar rates of burnout. For example, using tertiles, physician burnout as judged by EE was 39\% (30 out of 76), by D it was 34\% (26/76), and by PA it was $41 \%$ (31/75). Using cut points suggested by Leiter and Maslach $^{17}, 39 \%$ of physicians were classified with burnout for EE; although, this method showed only 9\% with burnout for D. Importantly, over $22 \%$ (17 of 76) scored high on both EE and D as measured by tertiles; this may be indicative of more serious burnout for these physicians.

Table 3 compares aMBI constructs with demographic characteristics. Except for working with medical students, characteristics were not significantly different by the constructs. However, the sample size was small and some differences may be meaningful. For example, females had higher median scores (more burnout) for both EE and D compared to males. Primary care physicians scored higher for EE and D and slightly lower for PA than either surgeons or subspecialty physicians. Compared to those in private practice, hospital-employed physicians scored higher for EE and D.
Table 1. Demographic characteristics of responding physicians.

\begin{tabular}{|c|c|c|c|}
\hline Characteristic & Response & $\mathbf{n}$ & $\%$ \\
\hline \multirow[t]{2}{*}{ Gender } & Male & 51 & 67.1 \\
\hline & Female & 25 & 32.9 \\
\hline \multirow[t]{5}{*}{ Age } & $<30$ & 2 & 2.6 \\
\hline & $30-39$ & 19 & 25.0 \\
\hline & $40-49$ & 26 & 34.2 \\
\hline & $50-59$ & 12 & 15.8 \\
\hline & $60+$ & 17 & 22.4 \\
\hline \multirow[t]{5}{*}{ Years Practicing } & $0-5$ & 18 & 23.7 \\
\hline & $6-10$ & 10 & 13.2 \\
\hline & $11-15$ & 14 & 18.4 \\
\hline & $16-20$ & 9 & 11.8 \\
\hline & $>20$ & 25 & 32.9 \\
\hline \multirow[t]{3}{*}{ Type of Provider } & Primary Care & 36 & 47.4 \\
\hline & Surgery & 18 & 23.7 \\
\hline & Subspecialty & 22 & 28.9 \\
\hline \multirow[t]{2}{*}{ Type of Practice } & Private Practice & 35 & 46.1 \\
\hline & Hospital-employed & 41 & 53.9 \\
\hline \multirow[t]{2}{*}{$\begin{array}{l}\text { Work with KUSM Students } \\
\text { (classroom teaching or on clinical } \\
\text { rotations) }\end{array}$} & Yes & 59 & 77.6 \\
\hline & No & 17 & 22.4 \\
\hline \multirow[t]{2}{*}{ If yes, do you primarily instruct } & $\begin{array}{c}\text { Attending } \\
\text { (M3s and M4s) }\end{array}$ & 56 & 94.9 \\
\hline & $\begin{array}{l}\text { Basic Sciences } \\
\text { (M1s and M2s) } \\
\end{array}$ & 3 & 5.1 \\
\hline \multirow[t]{5}{*}{$\begin{array}{l}\text { If Attending, number of contact } \\
\text { weeks per year }\end{array}$} & $<2$ & 13 & 23.2 \\
\hline & $2-4$ & 11 & 19.6 \\
\hline & $4-8$ & 13 & 23.2 \\
\hline & $8-16$ & 9 & 16.1 \\
\hline & $16-24$ & 10 & 17.9 \\
\hline \multirow[t]{5}{*}{$\begin{array}{l}\text { If Basic Sciences, number of sessions } \\
\text { per year }\end{array}$} & 1 & 0 & 0.0 \\
\hline & 2 & 2 & 66.7 \\
\hline & 3 & 0 & 0.0 \\
\hline & 4 & 1 & 33.3 \\
\hline & 5 or more & 0 & 0.0 \\
\hline \multirow[t]{2}{*}{ Work with Residents? } & Yes & 50 & 65.8 \\
\hline & No & 26 & 34.2 \\
\hline \multirow[t]{8}{*}{ Number of on-call nights per week } & 0 & 12 & 15.8 \\
\hline & 1 & 22 & 28.9 \\
\hline & 2 & 18 & 23.7 \\
\hline & 3 & 9 & 11.8 \\
\hline & 4 & 6 & 7.9 \\
\hline & 5 & 2 & 2.6 \\
\hline & 6 & 0 & 0.0 \\
\hline & 7 & 7 & 9.2 \\
\hline
\end{tabular}


Table 2. Summary of Maslach construct scores and comparisons of cut points for indicating burnout.

\begin{tabular}{|c|c|c|c|c|c|c|}
\hline \multirow[b]{2}{*}{$\begin{array}{c}\text { Maslach } \\
\text { Constructs }^{\mathrm{b}}\end{array}$} & \multirow[b]{2}{*}{ n } & \multirow[b]{2}{*}{$\begin{array}{l}\text { Mean } \\
(\text { SD) }\end{array}$} & \multirow[b]{2}{*}{$\begin{array}{l}\text { Median } \\
(\min , \text { max })\end{array}$} & \multicolumn{3}{|c|}{$\begin{array}{c}\text { Burnout per Cut-Point } \\
\text { Method }^{\mathrm{a}} \\
\text { n (\%) }\end{array}$} \\
\hline & & & & Tertile & $\begin{array}{l}\text { Leiter \& } \\
\text { Maslach }^{17}\end{array}$ & $\begin{array}{c}\text { Lebares } \\
\text { et al. }{ }^{22}\end{array}$ \\
\hline $\begin{array}{l}\text { Emotional } \\
\text { Exhaustion }(\mathrm{EE})^{\mathrm{c}}\end{array}$ & 76 & $\begin{array}{c}8.4 \\
(4.9) \\
\end{array}$ & $\begin{array}{c}8 \\
(0,18) \\
\end{array}$ & $\begin{array}{c}30 \\
(0.39) \\
\end{array}$ & $\begin{array}{c}30 \\
(0.39) \\
\end{array}$ & $\begin{array}{c}35 \\
(0.46) \\
\end{array}$ \\
\hline $\begin{array}{l}\text { Depersonalization } \\
\text { (D) }{ }^{c}\end{array}$ & 76 & $\begin{array}{c}4.5 \\
(3.9)\end{array}$ & $\begin{array}{c}3.5 \\
(0,16)\end{array}$ & $\begin{array}{c}26 \\
(0.34)\end{array}$ & $\begin{array}{c}7 \\
(0.09)\end{array}$ & $\begin{array}{c}26 \\
(0.34)\end{array}$ \\
\hline $\begin{array}{l}\text { Personal } \\
\text { Accomplishment } \\
\text { (PA) }\end{array}$ & $75^{\mathrm{b}}$ & $\begin{array}{l}15.3 \\
(2.8)\end{array}$ & $\begin{array}{c}16 \\
(4,18)\end{array}$ & $\begin{array}{c}31 \\
(0.41)\end{array}$ & $\begin{array}{c}31 \\
(0.41)\end{array}$ & $\begin{array}{c}12 \\
(0.16)\end{array}$ \\
\hline
\end{tabular}

Note: 17 of 76 (22.4\%) physicians scored high on both Emotional Exhaustion and Depersonalization constructs as measured by the tertile cut points.

aEmotional Exhaustion (EE) cut points to indicate burnout:

- EE upper tertile $\geq 11$

- $\mathrm{EE} \geq 10.85$ (standardized $\mathrm{z}$ values; Leiter and Maslachl7: $\mathrm{z}=$ mean $+(\mathrm{SD}$ * 0.5))

- $\mathrm{EE} \geq 9$ (per Lebares et al.22, surgery residents)

Depersonalization (D) cut points to indicate burnout:

- D upper tertile $\geq 6$

- $\mathrm{D} \geq 9.38$ (standardized z values; Leiter and Maslachl7: $\mathrm{z}=$ mean $+(\mathrm{SD} * 1.25)$ )

- $\mathrm{D} \geq 6$ (per Lebares et al.22, surgery residents)

Personal Accomplishments (PA) cut points to indicate greater personal accomplishment:

- PA lower tertile $\leq 15$

- $\mathrm{PA} \leq 15.58$ (standardized $\mathrm{z}$ values; Leiter and Maslachl7: $\mathrm{z}=$ mean $=(\mathrm{SD} * 0.10)$ )

- PA $\leq 12$ (once weekly positive interactions)

aPossible scores range from $0-18$.

${ }^{b}$ Higher scores for EE and D indicate greater emotional exhaustion, and greater burnout. Higher scores for PA indicate greater personal accomplishment, and less burnout.

${ }^{c}$ One respondent did not answer the question: I deal very effectively with the problems of my patients.

With regards to engagement in teaching, physicians who did not work with medical students scored higher (more burnout) on EE than those who worked with them. Significant differences were observed in PA among physicians working with medical students versus those with no teaching responsibilities $(p=0.037)$. However, using a Bonferroni correction for multiple tests, this result is trivial. Those physicians working with residents scored higher on D than those who did not work with them. Paradoxically, those who did not work with residents scored higher on EE than those who worked with them. Physicians in the high teaching category (a derived score from contact time with both medical students and residents) had higher median values for $\mathrm{EE}$ and $\mathrm{D}$ compared with physicians with low or no teaching responsibilities. Nevertheless, statistical analysis showed minimal correlation of EE, D, or PA scores with level of teaching (rho $=-0.015,-0.074$, and 0.208 , respectively). Similar lack of associations to burnout scores were observed for number of on-call nights per week, teaching in the basic science years (years 1 and 2) versus the clerkship years (years 3 and 4), or contact hours per year with students.

When queried as to "What causes you to feel burned out?", the top two responses were: "documentation requirements" and "dealing with difficult patients". Other common key words found in free-text responses included: "unhappiness with administration", "administrative duties", "long hours", "poor patient outcomes", and "lack of sleep” (Figure 1). "True time off" and "time with family" were the top two responses to the question, "What helps you to feel less burned out?". Other common response key words included: time doing hobbies, positive feedback, positive outcomes, helping patients, and exercise (Figure 2).
KANSAS JOURNAL of MEDICINE

\section{PHYSICIAN BURNOUT}

continued.

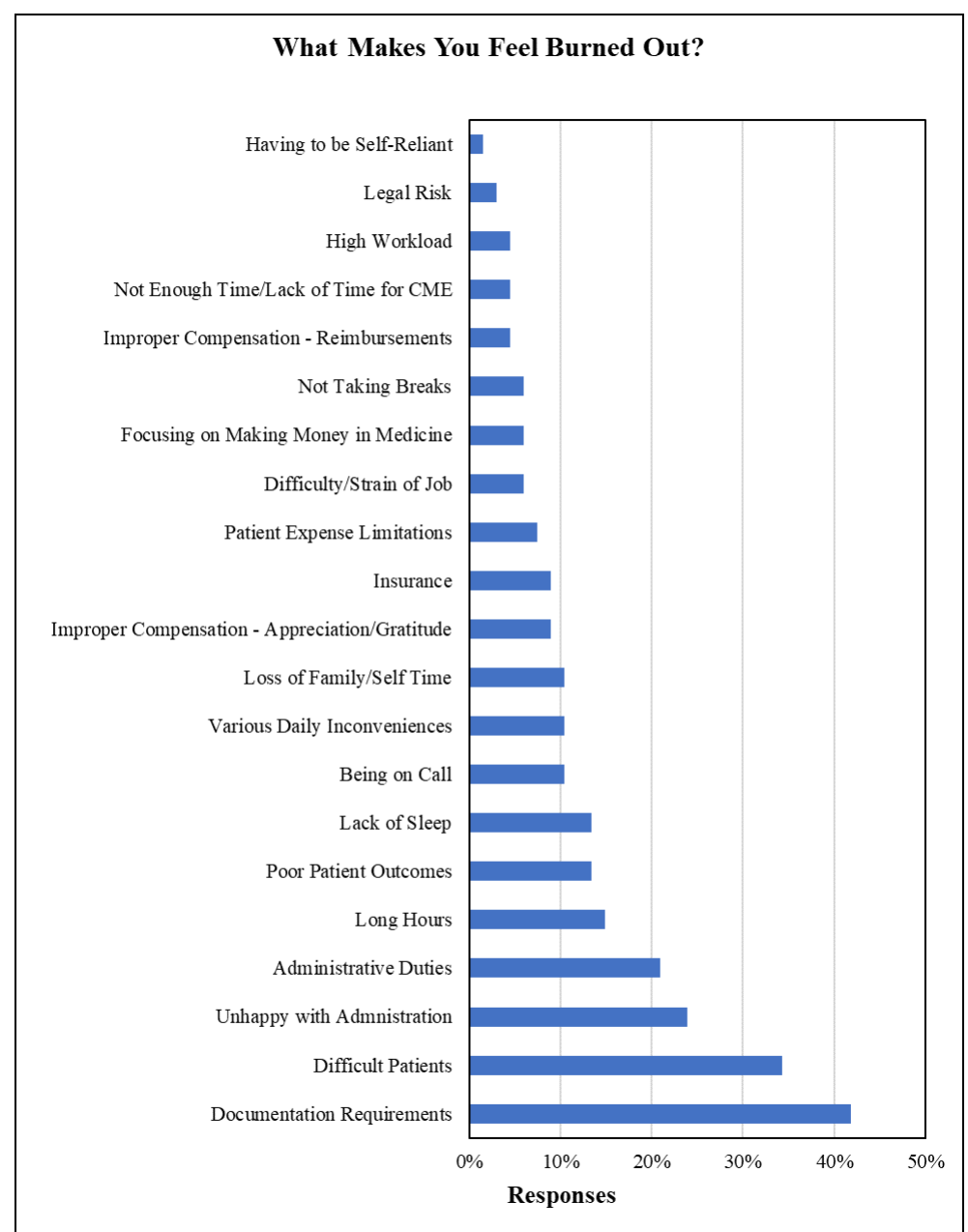

Figure 1. Key word response rate to open-ended question $\# 1$.

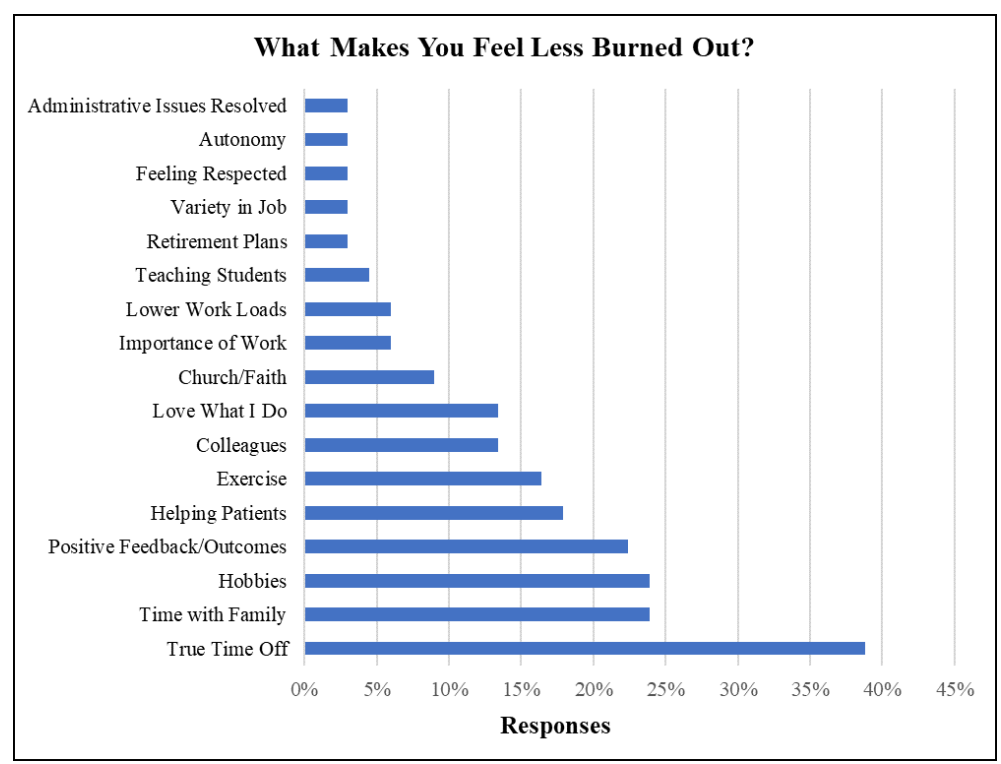

Figure 2. Key word response rate to open-ended question $\# 2$. 


\section{KANSAS JOURNAL of MEDICINE}

PHYSICIAN BURNOUT

continued.

Table 3. Comparisons of aMBI constructs by demographic characteristics.

\begin{tabular}{|c|c|c|c|c|c|c|c|c|c|c|}
\hline & & \multicolumn{3}{|c|}{ Emotional Exhaustion* } & \multicolumn{3}{|c|}{ Depersonalization* } & \multicolumn{3}{|c|}{ Personal Accomplishment** } \\
\hline Characteristics & $\mathbf{n}$ & Median & Mean & SD & Median & Mean & SD & Median & Mean & SD \\
\hline
\end{tabular}

Gender

\begin{tabular}{|l|c|c|c|c|c|c|c|c|c|c|}
\hline Male & $51(67.1)$ & 8.0 & 8.0 & 5.1 & 3.0 & 4.4 & 4.5 & 16.0 & 15.4 & 2.6 \\
\hline Female & $25(32.9)$ & 9.0 & 9.3 & 4.5 & 5.0 & 4.6 & 2.5 & 16.0 & 15.0 & 3.2 \\
\hline Mann-Whitney U exact p-value & & 0.199 & & & 0.216 & & & 0.648 & & \\
\hline
\end{tabular}

Age

\begin{tabular}{|l|c|c|c|c|c|c|c|c|c|c|c|}
\hline$<30$ & $2(2.6)$ & 5.0 & 5.0 & 5.7 & 3.0 & 3.0 & 4.2 & 17.5 & 17.5 & 0.7 \\
\hline $30-39$ & $19(25.0)$ & 9.0 & 9.2 & 4.5 & 3.0 & 4.6 & 4.0 & 16.0 & 15.5 & 2.1 \\
\hline $40-49$ & $26(34.2)$ & 7.5 & 8.7 & 4.5 & 3.5 & 3.8 & 3.1 & 16.0 & 15.4 & 2.7 \\
\hline $50-59$ & $12(15.8)$ & 5.5 & 7.3 & 5.0 & 4.0 & 5.9 & 5.7 & 15.0 & 15.0 & 2.3 \\
\hline $60+$ & $17(22.4)$ & 9.0 & 8.4 & 6.0 & 4.0 & 4.5 & 3.6 & 17.0 & 14.9 & 3.9 \\
\hline Kruskal Wallis test; p-value & & 0.645 & & & 0.900 & & & 0.555 & & \\
\hline
\end{tabular}

Type of Practice

\begin{tabular}{|c|c|c|c|c|c|c|c|c|c|c|}
\hline Private Practice & $35(46.1)$ & 6.0 & 7.5 & 5.0 & 2.0 & 3.8 & 3.7 & 16.5 & 15.3 & 3.1 \\
\hline Hospital Employed & $41(53.9)$ & 9.0 & 9.2 & 4.7 & 4.0 & 5.0 & 4.1 & 16.0 & 15.3 & 2.6 \\
\hline Mann-Whitney U exact p-value & & 0.129 & & & 0.165 & & & 0.766 & & \\
\hline
\end{tabular}

Type of Provider

\begin{tabular}{|l|c|c|c|c|c|c|c|c|c|c|c|}
\hline Primary Care & $36(47.4)$ & 9.0 & 9.5 & 4.2 & 4.5 & 5.1 & 4.0 & 16.0 & 15.2 & 2.4 \\
\hline Surgery & $18(23.7)$ & 6.0 & 7.9 & 5.3 & 3.5 & 4.8 & 4.2 & 17.0 & 15.4 & 2.6 \\
\hline Subspecialty & $22(28.9)$ & 5.0 & 7.2 & 5.6 & 2.0 & 3.2 & 3.4 & 17.0 & 15.3 & 3.6 \\
\hline Kruskal Wallis test; p-value & & 0.131 & & & 0.115 & & & 0.637 & & \\
\hline If subspecialty, do you perform procedures? & & & \\
\hline Yes & $20(90.9)$ & 5.0 & 7.2 & 5.6 & 2.0 & 3.3 & 3.5 & 17.0 & 15.1 & 3.8 \\
\hline No & $2(9.1)$ & 7.0 & 7.0 & 7.1 & 2.5 & 2.5 & 3.5 & 17.0 & 17.0 & 1.4 \\
\hline
\end{tabular}

Years Practicing

\begin{tabular}{|c|c|c|c|c|c|c|c|c|c|c|}
\hline $0-5$ & $18(23.7)$ & 10.0 & 9.1 & 4.6 & 3.0 & 4.6 & 4.1 & 16.0 & 15.6 & 2.2 \\
\hline $6-10$ & $10(13.2)$ & 4.0 & 6.5 & 5.1 & 4.0 & 3.4 & 2.2 & 17.0 & 16.5 & 1.3 \\
\hline $11-15$ & $14(18.4)$ & 9.5 & 9.9 & 3.8 & 4.0 & 4.4 & 3.7 & 16.0 & 14.4 & 3.3 \\
\hline $16-20$ & $9(11.8)$ & 11.0 & 11.1 & 4.8 & 2.0 & 4.7 & 5.4 & 15.0 & 15.3 & 2.6 \\
\hline $21-25$ & $10(13.2)$ & 5.0 & 6.4 & 4.8 & 4.0 & 5.4 & 4.9 & 15.5 & 15.4 & 1.7 \\
\hline $30+$ & 15 (19.7) & 8.0 & 7.3 & 5.5 & 4.0 & 4.4 & 3.5 & 17.0 & 14.8 & 4.2 \\
\hline Kruskal Wallis test; p-value & & 0.116 & & & 0.985 & & & 0.700 & & \\
\hline \multicolumn{11}{|l|}{ Number of on-call nights per week } \\
\hline 0 & $12(15.8)$ & 8.5 & 8.4 & 4.2 & 4.0 & 4.9 & 4.2 & 15.5 & 15.2 & 2.5 \\
\hline 1 & $22(28.9)$ & 8.5 & 9.1 & 4.3 & 3.5 & 4.0 & 3.6 & 15.0 & 14.6 & 2.7 \\
\hline 2 & $18(23.7)$ & 7.0 & 8.4 & 5.4 & 3.5 & 5.1 & 4.5 & 16.0 & 15.0 & 3.6 \\
\hline 3 & $9(11.8)$ & 4.0 & 4.7 & 3.6 & 2.0 & 2.7 & 3.1 & 17.0 & 16.4 & 2.1 \\
\hline 4 & $6(7.9)$ & 11.5 & 9.7 & 6.7 & 4.5 & 4.8 & 5.0 & 14.5 & 14.3 & 3.0 \\
\hline 5 & $2(2.6)$ & 10.0 & 10.0 & 8.5 & 6.5 & 6.5 & 3.5 & 17.0 & 17.0 & 0.0 \\
\hline 7 & $7(9.2)$ & 7.0 & 9.9 & 5.2 & 6.0 & 5.3 & 3.5 & 17.0 & 17.3 & 0.8 \\
\hline Kruskal Wallis test; p-value & & 0.343 & & & 0.561 & & & 0.072 & & \\
\hline \multicolumn{11}{|c|}{ Work with medical students and residents } \\
\hline Yes & $65(85.5)$ & 8.0 & 8.4 & 4.9 & 4.0 & 4.4 & 4.0 & 16.0 & 15.4 & 2.8 \\
\hline No & $11(14.5)$ & 8.0 & 8.6 & 5.1 & 3.0 & 4.8 & 3.5 & 15.0 & 14.6 & 2.7 \\
\hline Mann-Whitney U exact p-value & & 0.898 & & & 0.536 & & & 0.296 & & \\
\hline
\end{tabular}


KANSAS JOURNAL of MEDICINE

PHYSICIAN BURNOUT

continued.

\begin{tabular}{|c|c|c|c|c|c|c|c|c|c|c|}
\hline \multirow{2}{*}{ Characteristics } & \multirow[b]{2}{*}{$\mathbf{n}$} & \multicolumn{3}{|c|}{ Emotional Exhaustion* } & \multicolumn{3}{|c|}{ Depersonalization* } & \multicolumn{3}{|c|}{ Personal Accomplishment** } \\
\hline & & Median & Mean & SD & Median & Mean & SD & Median & Mean & SD \\
\hline \multicolumn{11}{|c|}{ Work with medical students (classroom teaching or on clinical rotations) } \\
\hline Yes & $59(77.6)$ & 7.0 & 8.2 & 4.9 & 4.0 & 4.2 & 3.6 & 16.5 & 15.6 & 2.7 \\
\hline No & $17(22.4)$ & 9.0 & 9.4 & 5.0 & 3.0 & 5.4 & 4.9 & 15.0 & 14.2 & 2.8 \\
\hline Mann-Whitney U exact p-value & & 0.404 & & & 0.520 & & & 0.037 & & \\
\hline \multicolumn{11}{|l|}{ If yes, do you primarily instruct } \\
\hline Attending (MS-3s, MS-4s) & $56(94.9)$ & 7.0 & 8.1 & 4.9 & 4.0 & 4.3 & 3.6 & 16.0 & 15.6 & 2.8 \\
\hline Basic Sciences (MS-1s, MS-2s) & $3(5.1)$ & 11.0 & 8.3 & 4.6 & 2.0 & 3.3 & 4.2 & 18.0 & 17.0 & 1.7 \\
\hline Mann-Whitney U exact p-value & & 0.996 & & & 0.643 & & & 0.285 & & \\
\hline \multicolumn{11}{|c|}{ If Attending, number of contact weeks per year } \\
\hline$<2$ & $13(23.2)$ & 6.0 & 6.8 & 5.3 & 4.0 & 3.7 & 3.1 & 17.0 & 16.2 & 1.7 \\
\hline $2-4$ & $11(19.6)$ & 8.0 & 9.0 & 4.9 & 2.0 & 4.1 & 4.0 & 13.5 & 12.8 & 4.4 \\
\hline $4-8$ & $13(23.2)$ & 9.0 & 9.7 & 4.6 & 6.0 & 6.4 & 4.4 & 16.0 & 15.3 & 2.2 \\
\hline $8-16$ & $9(16.1)$ & 6.0 & 8.0 & 5.5 & 3.0 & 3.0 & 3.1 & 17.0 & 16.7 & 1.4 \\
\hline $16-24$ & $10(17.9)$ & 5.5 & 7.1 & 4.7 & 3.5 & 3.6 & 2.3 & 17.0 & 16.7 & 1.3 \\
\hline Kruskal Wallis test; p-value & & 0.511 & & & 0.259 & & & 0.058 & & \\
\hline \multicolumn{11}{|c|}{ If Basic Sciences, number of sessions per year } \\
\hline 2 & $2(66.7)$ & 7.0 & 7.0 & 5.7 & 1.0 & 1.0 & 1.4 & 18.0 & 18.0 & 0.0 \\
\hline 4 & $1(33.3)$ & 11.0 & 11.0 & . & 8.0 & 8.0 & . & 15.0 & 15.0 & 0.0 \\
\hline \multicolumn{11}{|l|}{ Work with residents? } \\
\hline Yes & $50(65.8)$ & 7.5 & 8.2 & 4.8 & 4.0 & 4.8 & 4.0 & 16.0 & 15.6 & 2.3 \\
\hline No & $26(34.2)$ & 8.5 & 8.8 & 5.1 & 2.5 & 3.9 & 3.8 & 16.0 & 14.6 & 3.6 \\
\hline Mann-Whitney U exact p-value & & 0.681 & & & 0.297 & & & 0.330 & & \\
\hline \multicolumn{11}{|l|}{ Teaching level $^{\mathrm{a}}$} \\
\hline Low & $35(46.1)$ & 7.0 & 8.2 & 5.0 & 2.0 & 4.1 & 4.3 & 16.0 & 14.9 & 3.4 \\
\hline High & $30(39.5)$ & 8.5 & 8.6 & 4.9 & 4.5 & 4.8 & 3.7 & 17.0 & 16.0 & 1.9 \\
\hline Not a mentor & $11(14.5)$ & 8.0 & 8.6 & 5.1 & 3.0 & 4.8 & 3.5 & 15.0 & 14.6 & 2.7 \\
\hline Kruskal Wallis test; p-value & & 0.924 & & & 0.385 & & & 0.326 & & \\
\hline
\end{tabular}

*Higher scores indicate more burnout.

** Score not available for one physician due to missing data.

aTeaching level was derived from the amount of contact with both medical students and residents.

Alpha level criterion for significance includes Bonferroni correction $=0.05 / 36$ tests $=0.00139$; thus, no characteristic was significantly associated with the three aMBI constructs

\section{DISCUSSION}

Burnout is a prevalent problem in the physician community. It negatively impacts the lives of physicians in many ways, both personally (contributing to broken relationships, substance abuse, and suicidal ideation) and professionally (linked to increased medical errors and decreased quality of care for patients). ${ }^{4-7,23}$ Although direct comparison with previous studies on physician burnout is difficult due to differences in survey methods and scoring, our findings of the prevalence of physician burnout mirror those of other researchers. In a study of U.S. physicians, Shanafelt et al. ${ }^{24}$ reported that $45.8 \%$ of respondents had at least one symptom of burnout. In a national survey of U.S. general surgery residents, Elmore et al. ${ }^{11}$ found that $69 \%$ of those surveyed met the criterion for burnout on at least one subscale. Shanafelt and colleagues ${ }^{25}$ surveyed burnout in American surgeons and reported that $40 \%$ of respondents were burned out. The 2015 Medscape Physician Lifestyle Report ${ }^{26}$ noted burnout rates in U.S. physicians varied from a low of $37 \%$ in dermatologists to a high of $53 \%$ in critical care physicians.

Though most of our multivariate analysis showed no statistically significant differences between burnout rates for different demographic groups, women, primary care physicians, and hospitalemployed physicians tended to have higher burnout scores. Salina physicians working with medical students had significantly higher PA scores compared to those physicians who did not teach medical students. This finding supported other studies showing that medical students have a positive effect on the physicians engaged in teaching. ${ }^{16,27,28}$ It is gratifying to find that established physicians who participate in the education of the next generation of physicians have an increased sense of personal accomplishment.

Response to the open-ended questions at the end of the survey were revealing as to the major factors contributing to burnout and to those factors alleviating burnout. The most prevalent item 
KANSAS JOURNAL of MEDICINE PHYSICIAN BURNOUT

continued.

\section{CONCLUSION}

The problem of burnout is not confined to academic medical centers, surgeons, or large metropolitan areas. Burnout is also a significant problem for physicians practicing in rural areas. Burnout does not discriminate for gender, age, type of practice, employment model, length of practice, or engagement in teaching medical students and/or residents.

The epidemic levels of burnout, notably EE and D, determined in this survey and in other studies demonstrated the need for interventions to combat this serious problem. Drummond has proposed four tools for reducing burnout by finding work-life balance: (1) creating a life calendar (listing work commitments and recreational activities); (2) scheduling date nights; (3) creating a big bucket list (things you want to do before dying) and a weekly bucket list; and (4) creating a "clean, solid, functioning boundary between work and home."33 Shanafelt and Noseworthy ${ }^{34}$ stressed the importance of the organization's (health system's) role in reducing physician burnout and proposed organizational strategies to promote physician engagement and reduce burnout. Four important strategies were: acknowledgement of the problem, harnessing leadership to address the problem, promoting flexibility and work-life integration, and providing resources to promote resilience and self-care.

It is imperative that healthcare systems and physicians recognize that burnout is a major issue affecting physician well-being, productivity, and patient care. Once the problem is acknowledged, it is important that healthcare systems assist physicians in developing a plan to ameliorate burnout and improve physician well-being, and that physicians also take responsibility for developing strategies to combat the problem.

\section{ACKNOWLEDGEMENT}

Utilization of REDCap is supported by CTSA grant ULl TR002366 from NCRR and NCATS awarded to the University of Kansas Medical Center for Frontiers: University of Kansas Clinical and Translational Science Institute.

\section{REFERENCES}

${ }^{1}$ Maslach C, Jackson SE, Leiter MP. Maslach Burnout Inventory Manual. 4th edition. Palo Alto, CA: Mind Garden, Inc., 1996.

${ }^{2}$ Fred HL, Scheid MS. Physician burnout: Causes, consequences, and (?) cures. Tex Heart Inst J 2018; 45(4):198-202. PMID: 30374225.

3 Drummond D. Physician Burnout; Its origin, symptoms, and five main causes. Family Practice Management. 2015. Available at: http://www.aafp. org/fpm/2015/0900/p42.html. Accessed March 4, 2019.

4 Firth-Cozens J, Greenhalgh J. Doctors' perceptions of the links between stress and lowered clinical care. Soc Sci Med 1997; 44(7):1017-1022. PMID: 9089922.

${ }^{5}$ Shanafelt TD, Bradley KA, Wipf JE, Back AL. Burnout and self-reported patient care in an internal medicine residency program. Ann Intern Med 2002; 136(5):358-367. PMID: 11874308.

${ }^{6}$ Shanafelt TD, West C, Zhao X, et al. Relationship between increased personal well-being and enhanced empathy among internal medicine residents. J Gen Intern Med 2005; 20(7):559-564. PMID: 16050855.

7 Loerbroks A, Glaser J, Vu-Eickmann P, Angerer P. Physician burnout, work engagement and the quality of patient care. Occup Med (Lond) 2017; 67(5):356-362. PMID: 28510762.

${ }^{8}$ Sergay SM. The burnout patient. Neurol Clin Pract 2018; 8(4):346-348. PMID: 30140587.

9 National Academy of Medicine. Validated instruments to assess work-related dimensions of well-being. Available at: http://nam.edu/ valid-reliable-survey-instruments-measure-burnout-well-work-relateddimensions/. Accessed March 14, 2019. 
10 Shanafelt TD, Hasan O, Dyrbye LN, et al. Changes in burnout and satisfaction with work-life balance in physicians and the general US working population between 2011 and 2014. MAYO Clin Proc 2015; 90(12):16001613. PMID: 26653297.

${ }^{11}$ McManus IC, Winder BC, Gordon D. The causal links between stress and burnout in a longitudinal study of UK doctors. Lancet 2002; 359(9323):2089-2090. PMID: 12086767.

${ }^{12}$ McManus IC, Keeling A, Paice E. Stress, burnout and doctors' attitudes to work are determined by personality and learning style: A twelve year longitudinal study of UK medical graduates. BMC Med 2004; 2:29. PMID: 15317650 .

${ }^{13}$ Riley MR, Mohr DC, Waddimba AC. The reliability and validity of threeitem screening measures for burnout: Evidence from group-employed health care practitioners in upstate New York. Stress Health 2018; 34(1):187-193. PMID: 28524379.

14 Zuraida AS, Zainal NZ. Exploring burnout among Malaysian junior doctors using the abbreviated Maslach Burnout Inventory. Malaysian Journal of Psychiatry Ejournal. 2015. Available at: http://www.mjpsychiatry.org/index.php/mjp/article/view/348. Accessed March 4, 2019.

15 Elmore LC, Jeffe DB, Jin L, Awad MM, Turnbull IR. National survey of burnout among US general surgery residents. J Am Coll Surg 2016; 223(3):440-45l. PMID: 27238875.

16 Tijdink JK, Vergouwen AC, Smulders YM. Emotional exhaustion and burnout among medical professors; a nationwide survey. BMC Med Educ 2014; 14:183. PMID: 25189761.

17 Leiter MP, Maslach C. Latent burnout profiles: A new approach to understanding the burnout experience. Burn Res 2016; 3(4):89-100. DOI: 10.1016/j.burn.2016.09.001.

${ }_{18}$ Mind Garden. The problem with cut-offs for the Maslach Burnout Inventory. May 31, 2018. Available at: https://www.mindgarden.com/documents/MBI-Cutoff-Caveat.pdf. Accessed May 14, 2019.

19 Adams C, Cathcart-Rake W. Attending physician perceptions of the benefits and disadvantages of teaching medical students on clinical clerkships at a regional medical campus. J Reg Med Campuses 2018; 1(2). https://doi. org/10.24926/jrmc.vli2.1286. Accessed March 4, 2019.

${ }^{20}$ Cathcart-Rake W, Robinson M, Owings S, Kennedy M, Paolo A, Chumley H. The birth of a rural medical school - The University of Kansas School of Medicine-Salina Experience. Med Sci Educ 2012; 22(4):250-258.

${ }^{21}$ Harris PA, Taylor R, Thielke R, Payne J, Gonzalez N, Conde JG. Research electronic data capture (REDCap) - A metadata-driven methodology and workflow process for providing translational research informatics support. J Biomed Inform 2009; 42(2):377-381. PMID: 18929686.

${ }^{22}$ Lebares CC, Guvva EV, Ascher NL, O’Sullivan PS, Harris HW, Epel ES. Burnout and stress among US surgery residents: Psychological distress and resilience. J Am Coll Surg 2018; 226(1):80-90. PMID: 29107117.

${ }^{23}$ Williams ES, Skinner AC. Outcomes of physician job satisfaction: A narrative review, implications, and directions for future research. Health Care Manage Rev 2003; 28(2):119-139. PMID: 12744449.

24 Shanafelt TD, Boone S, Tan L, et al. Burnout and satisfaction with worklife balance among US physicians relative to the general US population. Arch Intern Med 2012; 172(18):1377-1385. PMID: 22911330.

25 Shanafelt TD, Balch CM, Bechamps GJ, et al. Burnout and career satisfaction among American surgeons. Ann Surg 2009; 250(3):463-471. PMID: 19730177.

${ }_{26}$ Peckham C. Medscape Physician Lifestyle Survey 2015. January 26, 2015. Available at: http://medscape.com/features/slideshow/lifestyle/2015/public/overview\#2. Accessed March 4, 2019.

27 Walters LS, Worley PS, Prideaux D, Rolfe H, Keaney C. The impact of medical students on rural general practitioner preceptors. Rural Remote Health 2005; 5(4):403. PMID: 16283828.

28 Pichlhfer O, Tönies H, Spiegel W, Wilhelm-Mitteräcker A, Maier M. Patient and preceptor attitudes towards teaching medical students in general practice. BMC Med Educ 2013; 13:83. PMID: 23758778.

${ }_{29}$ Gopal R, Glasheen JJ, Miyoshi TJ, Prochazka AV. Burnout and internal medicine resident work-hour restrictions. Arch Intern Med 2005; 165(22):2595-2600. PMID: 16344416.

${ }^{30}$ Goitein L, Shanafelt TD, Wipf JE, Slatore CG, Back AL. The effects of work-hour limitations on resident well-being, patient care, and education in an internal medicine residency program. Arch Intern Med 2005; 165(22):2601-2606. PMID: 16344417.

${ }_{31}$ Hutter MM, Kellogg KC, Ferguson CM, Abbott WM, Warshaw AL. The impact of the 80-hour resident workweek on surgical residents and attending physicians. Ann Surg 2006; 243(6):864-875. PMID: 16772790.
KANSAS JOURNAL of MEDICINE

PHYSICIAN BURNOUT

continued.

32 Baruch Y, Holtom BC. Survey response rate levels and trends in organizational research. Human Relations 2008; 61(8):1139-1160. DOI: 10.1177/0018726708094863.

33 Drummond D. Four tools for reducing burnout by finding work-life balance. Fam Pract Manag 2016; 23(1):28-33. PMID: 26761301.

34 Shanafelt TD, Noseworthy JH. Executive leadership and physician wellbeing: Nine organizational strategies to promote engagement and reduce burnout. Mayo Clin Proc 2017; 92(1):129-146. PMID: 27871627.

Keywords: professional burnout, rural population, job satisfaction, surveys and questionnaires 